\title{
Sistemas de classificação nominal no Sudoeste amazônico
}

\author{
Nominal classification systems in the Southwestern Amazon \\ Hein VAN DER VOORT* \\ Museu Paraense Emílio Goeldi (MPEG/MCTI)
}

\begin{abstract}
RESUMO: Enquanto línguas africanas são conhecidas por ter sistemas fechados e altamente gramaticalizados de classes flexionais de substantivos e sistemas de concordância de gênero, línguas asiáticas e austronésicas tipicamente têm sistemas relativamente abertos de uma natureza mais lexical, que envolvem múltiplos termos de medida e de classe. Considerando estes tipos de classificação nominal como extremos opostos em um espectro heterogêneo, sistemas de classificação nas línguas amazônicas tendem a ocupar uma posição intermediária. Em várias línguas amazônicas encontra-se um sistema léxico-grammatical de classificação que combina caraterísticas dos dois outros extremos. Esses sistemas tipicamente envolvem um número considerável de morfemas classificatórios presos, que têm uma distribuição ampla e que podem ter funções diversas, como concordância, anáfora e derivação. Essa caraterização não está limitada às línguas do Noroeste amazônico, mas vale também para várias línguas do Sudoeste amazônico. Além disso, é evidente que esses sistemas de classificação podem se espalhar arealmente.
\end{abstract}

PALAVRAS-CHAVE: Classificadores. Sudoeste amazônico. Difusão areal

ABSTRACT: Whereas African languages are known for closed and highly grammaticalised systems of nominal inflection classes and gender agreement systems, Asian and Austronesian languages typically have relatively open systems of a more lexical nature that involve multiple terms of class and measure. Considering these types of nominal classification as opposite extremes on a heterogenous scale, classification systems in Amazonian languages tend to occupy an intermediary position. In various Amazonian languages a lexico-grammatical system of classification is found that combines characteristics of both extremes. These systems typically involve a considerable number of bound classifying morphemes that have a wide distribution and that may have diverse functions such as agreement, anaphor, and lexical derivation. These characteristics are not limited to northwestern Amazonia, but they also hold for various languages of southwestern Amazonia. It is furthermore evident that those classification systems can spread areally.

KEY WORDS: Classifiers. Southwestern Amazonia. Areal diffusion

\section{Introdução}

No Sudoeste amazônico, que neste artigo é considerado como a região incluindo partes das terras baixas da Bolívia e do Brasil em ambos os lados do rios Guaporé/Iténez e Mamoré, são ainda faladas mais de cinquenta línguas indígenas. Essas línguas pertencem a seis famílias ou troncos linguísticos: Arawák, Macro-Jê, Nambikwara, Pano-Tacana,

\footnotetext{
* Pesquisador associado, Coordenação de Ciências Humanas (CCH), Área de Linguística, Museu Goeldi, Belém (PA). E-mail: hvoort@museu-goeldi.br
} 
Txapakúra e Tupí. Além disso, há ainda 11 línguas isoladas, ou seja, línguas que não são membros de famílias/troncos conhecidos: Aikanã, Canichana, Cayubaba, Iranxe/Mỹky, Itonama, Kanoê, Kwazá, Leko, Mosetén/Chimané, Movima, Yurakaré. É uma diversidade genético-linguística extrema, talvez a maior das Américas, que deve ser resultado de vários milênios de migração e desenvolvimento populacional. Uma das questões importantes para os linguistas é de natureza interdisciplinar: como exatamente surgiu esta diversidade e o que isso nos ensina sobre a pré-história do continente? Para refletir sobre essas questões, é necessário ter conhecimento detalhado e profundo sobre todas as línguas da região, na forma de gramáticas descritivas, dicionários, coleções de textos e documentação multimídia. Nesse respeito, há ainda muito a fazer, em um contexto em que, infelizmente, muitas destas línguas estão seriamente ameaçadas de extinção, devido à dizimação e desintegração das comunidades indígenas e a destruição do meio-ambiente pelos colonizadores, o que faz parte de um problema mundial.

Das aproximadamente 50 línguas que ainda sobrevivem na região, a metade tem menos de 50 falantes, e aproximadamente um terço tem 10 falantes ou menos. Felizmente, nos últimos 25 anos, desde que a "questão das línguas ameaçadas" foi colocada como prioridade na agenda dos linguistas (HALE et al. 1992), houve um grande número de projetos e iniciativas nacionais e internacionais para documentar e analisar as línguas da região, levando a descrições abrangentes de boa qualidade de quase 20 línguas do Sudoeste Amazônico. Esses trabalhos não só estão começando a possibilitar um melhor entendimento da diversificação interna das famílias linguísticas, dos contatos entre as línguas e das relações entre os povos da região, como também estão já levando a novas hipóteses tipológicas e teóricas sobre a língua humana em geral.

Apesar da grande diversidade genético-linguística, as línguas do Sudoeste amazônico, aqui definido como a região Guaporé-Mamoré, mostram semelhanças entre si. Mesmo sendo línguas não relacionadas, elas compartilham caraterísticas fonológicas, estruturas gramaticais e elementos lexicais e morfológicos, cruzando fronteiras genéticolinguísticas. Essas semelhanças são resultado de contatos milenares entre as línguas da região, que levaram a empréstimos e convergências. Quando se tratam de traços gramaticais encontrados numa região delimitada independentemente das relações familiares entre as línguas, pode-se falar de traços areais, resultado de difusão areal, numa determinada área linguística. O exemplo clássico de uma "área linguística" é a região 
balcânica. Há várias áreas linguísticas conhecidas no mundo, como a região caucasiana, a região báltica, o planalto da Etiópia, o sul e sudeste da Ásia, Indonésia do leste com Papua, o litoral noroeste da América do Norte, América Central, e o Noroeste amazônico. Resultados de trabalhos descritivos recentes mostram que também a região GuaporéMamoré representa ou contém uma ou algumas subáreas linguísticas.

Como mostrado em um artigo sucinto seminal por Crevels e van der Voort (2008), várias línguas da região Guaporé-Mamoré compartilham elementos lexicais, como palavras para banana, milho, galinha, marico, chicha, estrela, lua; morfemas gramaticais, como aplicativos, classificadores e outros; e estruturas gramaticais, como 'citativos' ${ }^{1}$ para expressar tempo e modo, a ordem possuidor-possuído, uma alta incidência de prefixos, número verbal, distinção entre inclusivo e exclusivo nos sistemas pronominais e, ainda, sistemas multifuncionais de classificação nominal. Neste artigo discutirei sistemas de classificação nominal em línguas da região GuaporéMamoré, as semelhanças e diferenças entre eles e a sua difusão.

\section{Sistemas de classificação gramatical}

$\mathrm{Na}$ linguística, sistemas de classificação representam maneiras de categorizar elementos nominais. Desde meados dos anos 70, a classificação nominal e a sua realização nas línguas do mundo começou a receber bastante atenção pelos linguistas. A classificação nominal pode ser feita de maneiras muito diferentes, seja na morfologia flexional, lexicalmente, ou por derivação, e é provavelmente por isso que Allan (1977) supõe que todas as línguas têm classificadores. Desde meados dos anos 80, classificação nominal nas línguas da América do Sul começou a assumir um papel maior nas discussões tipológicas sobre o assunto (por exemplo: PAYNE 1987, CRAIG 1986, DERBYSHIRE; PAYNE 1990, AIKHENVALD 2000, GRINEVALD 2000, GRINEVALD; SEIFART 2004). Enquanto línguas africanas são conhecidas por terem sistemas fechados e altamente gramaticalizados de classes flexionais para nomes (ou substantivos) e sistemas de concordância de gênero, as línguas asiáticas e austronésicas de modo típico apresentam sistemas relativamente abertos de natureza mais lexical, que envolvem múltiplos termos de medida e de classe. Considerando estes tipos de

\footnotetext{
1 Construções que não são necessariamente usadas para citação de fala, mas também para expressar desejos, intenções, tempo futuro, entre outros (vide VAN DER VOORT 2013).
} 
classificação nominal como extremos opostos em um espectro heterogêneo, os sistemas de classificação nas línguas amazônicas tendem a ocupar uma posição intermediária. A seguinte tabela resume a tipologia de sistemas de classificação e a terminologia envolvida, apresentada em uma "clina de gramaticalização":2

Tabela 1: Tipologia de sistemas de classificação nominal

\begin{tabular}{lll} 
LEXICAL & INTERMEDIÁRIO & GRAMMATICAL \\
\hline termos de medida & classificadores numéricos & marcadores de gênero \\
termos de classe & $\begin{array}{l}\text { classificadores sortais } \\
\text { classificadores mensurais } \\
\text { classificadores de nomes }\end{array}$ & \\
& classificadores verbais &
\end{tabular}

Em várias línguas amazônicas encontra-se sistemas léxico-gramaticais de classificação que combinam caraterísticas dos dois extremos. Esses sistemas tipicamente envolvem um número considerável de morfemas classificatórios presos, que têm uma distribuição ampla e que podem ter funções diversas, como concordância, anáfora e derivação. Porém, como Seifart e Payne (2007) afirmam, os sistemas do Noroeste amazônico representam um tipo coerente próprio e não devem ser considerados como sistemas "mistos" ou "múltiplos". Como van der Voort (no prelo) demonstra, essa caraterização não está restrita às línguas do Noroeste amazônico, mas vale também para várias línguas do Sudoeste amazônico. Além disso, já é evidente que os sistemas de classificação podem ser sujeitos a espalhamento areal.

Talvez surpreendentemente, Crevels e van der Voort (2008, p.167; 170) mencionam como um dos traços areais da região Guaporé-Mamoré a relativa ausência de classificadores. Somente três das 24 línguas investigadas apresentam sistemas de gênero (Warí, Movima e Mosetén), e somente oito destas línguas têm classificadores. No entanto, os sistemas de classificadores encontrados na região revelam tendências similares inegáveis: $1^{\mathrm{a}}$.) envolvem grande número de classificadores; $2^{\mathrm{a}}$.) os

\footnotetext{
2 Inglês: "cline of grammaticalisation”, que refere a uma escala gradual de elementos menos gramaticalizados a mais gramaticalizados. A terminologia em inglês correspondente a Tabela 1:

\begin{tabular}{lll} 
LEXICAL & INTERMEDIATE & GRAMMATICAL \\
\hline measure terms & numeral classifiers & gender markers \\
class terms & sortal classifiers & noun class markers \\
& mensural classifiers & \\
& noun classifiers & \\
& verbal classifiers &
\end{tabular}
}


classificadores são elementos gramaticais com conteúdos semânticos bastante lexicais; $3^{\text {a }}$.) os classificadores têm uma distribuição ampla, ocorrendo em várias posições gramaticais (em nomes, verbos, adjetivos, demonstrativos, etc.); $4^{\mathrm{a}}$.) às vezes as formas dos classificadores são parecidas; $5^{\mathrm{a}}$.) os sistemas mostram similaridades com os do Noroeste amazônico.

A seguir, apresento as distribuições e funções de classificadores no Sudoeste amazônico, baseadas em dados de 10 línguas indígenas. Na tabela 2 foram listadas as línguas com a sua classificação genética e localização geográfica:

Tabela 2: Línguas discutidas neste artigo ${ }^{3}$

\begin{tabular}{|c|c|c|c|}
\hline 1 & Kwazá & \multirow[t]{5}{*}{ ISOLADAS } & \multirow[t]{3}{*}{ Brasil } \\
\hline 2 & Kanoê & & \\
\hline 3 & Aikanã & & \\
\hline 4 & Movima & & \multirow[t]{2}{*}{ Bolívia } \\
\hline 5 & Itonama & & \\
\hline 6 & Latundê/Lakondê & NAMBIKWARA DO NORTE & Brasil \\
\hline 7 & Cavineña & PANO-TACANA & Bolívia \\
\hline 8 & Arikapú & JABUTÍ, MACRO-JÊ & Brasil \\
\hline 9 & Baure & ARAWÁK DO SUL & Bolívia \\
\hline 10 & Karo & RAMARAMA, TUPÍ & Brasil \\
\hline
\end{tabular}

\section{Nomes}

Várias línguas da região, que não são geneticamente relacionadas entre si, têm sistemas de classificadores multifuncionais com uma ampla distribuição. Os classificadores podem ocorrer em várias posições diferentes. A produtividade, funcionalidade e distribuição exata dos mesmos dependem da língua em questão, mas na maioria delas os classificadores são verificados como sufixos nominais encontráveis em nomes substantivos. Observem-se as semelhanças estruturais nos seguintes exemplos de línguas pertencentes às famílias Arawák, Nambikwara, Macro-Jê e Tupí e, ainda, incluindo quatro línguas isoladas:

\footnotetext{
3 Os dados das línguas Aikanã (ISOLADA), Kwazá (ISOLADA) e Arikapú (MACRO-JÊ) vêm do meu próprio trabalho no campo com falantes natívos destas línguas. Os valores aproximativas dos símbolos usados nos exemplos destas línguas correspondem com o Alfabeto Fonético Internacional (IPA), com exceção de $\langle y\rangle$, $\langle\ddot{u}\rangle$, $\langle x\rangle$, que representam [i], [y], [J], respectivamente. Os dados das outras línguas vêm de trabalhos por colegas, devidamente identificados na lista de referências. Serão mencionadas ainda outras línguas que ocupam um espaço marginal na discussão em foco no presente artigo.
} 
(1) yaki-so

(Baure, Danielsen 2007, p.97)

fogo-CL:pau

'lenha'

(2) tiporek-po'e

galinha-cabeça

'cabeça de galinha'

(3) 'wajh-ki'nin- 'te

açaí-CL:redondo-REF

'fruta de açaí'

(4) atxitxi-to

(Baure, Danielsen 2007, p.96)

milho-CL:caroço

'caroço de milho'

(Latundê, Telles 2002, p.185)

(Kwazá)

(5) mãdere-zu

(Aikanã)

machado-CL:osso

'cabo de machado'

(6) mutyry-ko-mũ

açaí-CL:Coco-CL:líquido

(Kanoê, Bacelar 2004, p.102)

'vinho de açaí'

(7) kape:-vas

café-BR:farinha

'café em pó'

(8) $\quad m \tilde{r} \tilde{\varepsilon}-k a$

caba-CL:fruta

'ninho de cabas'

(Movima, Haude 2006, p.211)

(9) må̃e ká?

(Karo, Gabas Jr. 1999, p.217)

panela CL:concavo

'panela'

(Arikapú)

Entre as funções dos classificadores, está a criação de novas palavras derivadas, como nos exemplos (5), (3), (6) e (8). Outros exemplos mostram modificações nominais mais transparentes com interpretações mais previsíveis, como em (1) e (4). Nota-se que o elemento preso no exemplo (7), da língua Movima, não representa um classificador. Haude (2006) analisa estes elementos como raízes nominais presas, que podem ter funções similares às de classificadores.

As línguas Arikapú (8) e Karo (9) têm um número relativamente pequeno de classificadores. Os classificadores do Karo ocorrem somente com substantivos, e, como Gabas (1999, p.228) observa, o sistema do Karo mostra propriedades tipológicas tanto 
do extremo lexical (opcionalidade, morfemas livres) como do extremo gramatical (poucos itens, concordância, cf. Tabela 1). Às vezes é difícil fazer a distinção entre substantivos modificados por classificadores e substantivos compostos. O exemplo (2) mostra uma estrutura composta em Baure, onde o segundo membro da composição pode funcionar como classificador. Veja Aikhenvald (1994) para um tratamento extenso de classificadores nas línguas Aruák.

\section{Verbos}

Classificadores de várias destas mesmas línguas também podem ocorrer incorporados em verbos. Porém, essa posição de ocorrência é mais rara. Observem-se os seguintes exemplos de línguas Arawák, Nambikwara e duas línguas isoladas:

(10) ro=aromo-se-wapa to yašor (Baure, Danielsen 2007, p.208) 3SG.M=afundar-CL:oval-COS ART barco

'O barco afundou.'

(11) $r o=n i-p o-a-p o$ šep (Baure, Danielsen 2007, p.209) 3SG.M=comer-CL:pequenininho-LK-PRFLX chivé 'Ele comeu chivé (farinha de mandioca torrada).'

(12) oh-(ke’jat)-ki’nĩn- 'tã:n (Latundê, Telles 2002, p.244) socar-(milho)-CL:redondo-1SG.IMPF

'Estive socando caroços (de milho),'

(13) 'hu? sipi 'pi- 'kah- 'tãn-ta (Latundê, Telles 2002, p.191)

arco pequeno-CL:comprido-IMPF-ANT

'O arco é pequeno.'

(14) 'mãn-ka'loh

'hãn-ka'loh- 'tãn-ta (Latundê, Telles 2002,191)

roupa-CL:plano

branco-CL:plano-IMPF-ANT

'As roupas estão limpas.'

(15) awãta-xy-da-ki

(Kwazá)

ver-CL:folha-1SG-DEC

'Estou olhando no papel.'

(16) aky-djay-tse

(Kwazá)

dois-CL:cobra-DEC

'Tem dois cobras/lacráias/etc,'

(17) wai-xy-ki

(Kwazá)

bom-CL:casa-DEC

'É uma casa bonita.' (não: 'uma boa casa') 
(18) hitsa wikere taw-ka-pa-ẽ (Aikanã)

eu amendoim quebrar-1SG-CL:grande-DEC

'Quebrei amendoim.'

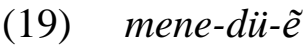

(Aikanã)

fresco-CL:ramo-DEC

'O ramo está fresco.'

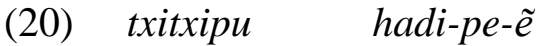

grilo vermelho-CL:redondo-DEC

(Aikanã)

'O grilo é vermelho.'

Os exemplos mostram como os classificadores podem ter funções anafóricas, referindo a ou concordando com o objeto do verbo (exemplos 11, 12, 15, 18) ou com o sujeito $(10,13,14,16,17,19,20)$. Em Movima há incorporação de substantivos ao verbo. Na língua Itonama há dois sistemas de classificadores separados: um que somente ocorre com substantivos e outro que somente ocorre com verbos (CREVELS 2012).

\section{Outras categorias}

$\mathrm{Na}$ grande maioria dos casos, os hospedeiros de classificadores nas línguas da região são substantivos e verbos. Nas línguas Karo e Cavineña existe uma categoria de adjetivos. Em Cavineña esses não ocorrem com classificadores, mas em Karo existe uma concordância obrigatória, se um substantivo classificado é modificado por um adjetivo:

$$
\begin{aligned}
& \text { naryopcí? cú cí? (Karo, Gabas Jr. 1999, p.225) } \\
& \text { folha CL:fino.plano grande CL:fino.plano }
\end{aligned}
$$

É possível argumentar que classificadores também ocorrem com raízes adjetivais, numerais e demonstrativos nas línguas Kwazá e Latundê, mas essas raízes são de natureza verbal. De outro modo, há alguns casos raros de classificadores ocorrendo com advérbios em Kwazá:

$$
\begin{aligned}
& \text { a-toto- } x y \\
& \varnothing \text {-DR:para.cima-CL:casa } \\
& \text { 'em cima da casa' }
\end{aligned}
$$


(23)

tsiritsa-mũ

(Kwazá)

meio-CL:líquido

'no meio do rio'

\section{Nominalização}

Em poucas línguas da região classificadores podem ter um efeito nominalizador.

Stricto sensu, isso foi atestado somente em Latundê e Kwazá.

$$
\begin{aligned}
& \text { 'la }{ }^{2}-n i \text { - 'te } \\
& \text { novo-CL:hemisférico-REF }
\end{aligned}
$$

'casa nova'

(25) pan-ki'nin-'te dois-CL:redondo-REF

'dois inhames'
axy-dy-xa-tsy-kane
$a w \tilde{y} i-d a-k i$
casa-CAUS-2-POT-CL:tábua ver-1SG-DEC
'Vi tábuas para você fazer uma casa.'

(Latundê, Telles 2002, p.200)

Em Movima, raízes nominais presas podem ter a capacidade de nominalizar verbos:
as am-a:-bun-ra
(Movima, Haude 2006, p.478)
ART.N entrar-BDR-BR:massa-BE:neutro
'a coisa em que coloquei a massa'

Nas línguas isoladas Kanoê e Aikanã, classificadores são sufixados em raízes verbais, mas eles não têm um poder nominalizador, porque necessitam ainda de morfemas nominalizadores específicos:
(28) etsivi-kwa-e
(Kanoê, Bacelar 2004, p.112)
urinar-CL:pequeno-NOM
'bexiga'
(29) txitxipu hadi-pe-i
gafanhoto vermelho-CL:redondo-NOM
'gafanhoto vermelho'
(Aikanã)

\section{Origem nominal}

Classificadores tendem a ser reflexos de substantivos presos e semanticamente “desbotados". Onde há dados relevantes à questão da origem de classificadores, a sua 
origem etimológica mostra-se ser nominal. Em Kanoê e Kwazá, classificadores não ocorrem como morfemas livres, mas muitos classificadores são etimologicamente relacionados a substantivos existentes na língua. Em Kwazá, por exemplo, os substantivos tsoro 'braço', dihu 'colher', deda 'cobra' provavelmente deram origem aos classificadores -koro 'braço, ramo', -tehu 'colher', -djay 'cobra/lacráia/centopéia', respectivamente. Em algumas línguas com sistemas de classificação, certos substantivos podem também ocorrer como classificadores, por exemplo, em Baure e em Aikanã:

(30a) po-mes-is

(Baure, Danielsen 2007, p.145)

um-mesa-um

'uma mesa'

(30b) po-amoko-š

mes

(Baure, Danielsen 2007, p.145)

um-CL:plano.elevado-um

mesa

'uma mesa'

(31) küri=ji

babaçu=folha

'palha de babaçu'

(Aikanã)

(32) (ji) txiri-di-ẽ

folha murchar-CL:folha -DEC

'A folha está murchando.'

Os classificadores nas línguas Nambikwara do Norte (Mamaindê e Latundê) são bem parecidos. São morfemas presos, contudo eles foram atestados em Latundê também como morfemas livres, enquanto isso não é possível em Mamaindê:

ka'loh 'â?

CL:plano grande-IMPF-ANT

(Aikanã)

'A tábua é grande.', 'As roupas são grande.', etc.

(34) mãn-kalo-tu

quente-CL:plano-FNS

(Mamaindê, Eberhard 2009, p.504)

'roupa/coisa plana e quente'

\section{Classificador genérico}

Em algumas línguas da região, o classificador faz parte obrigatória da estrutura de certos tipos de palavras. Se não há um classificador relevante ou se o falante não o quer especificar, o campo obrigatório é preenchido com um elemento semanticamente 
neutro. Em Movima existe um "elemento preso", -ra, para esse papel. Comparem-se os exemplos (35) e (36):

$\begin{array}{lll}\text { tas-poy } & \text { is } & \text { paj-i (Movima, Haude 2006, p.208) } \\ \text { três-BR:animal } & \text { ART.PL } & \text { BR:golfinho- } \varnothing\end{array}$

'Há três golfinhos.'

$\begin{array}{lll}\text { tas-ra } & \text { is } & \text { paj-i (Movima, Haude 2006, p.208) } \\ \text { três-BE:neutral } & \text { ART.PL } & \text { BR:golfinho- } \varnothing \\ \text { 'Há três golfinhos.' } & & \end{array}$

Em Kwazá o campo obrigatório do classificador pode ser preenchido pelo nominalizador $-h \tilde{y}$ :

(37) awãta-hy-da-ki

(Kwazá)

ver-NOM-1SG-DEC

'Estou vendo ele.', 'Estou olhando.'

Em Aikanã, não existe um campo obrigatório para classificadores:

(38) atti tsapi-ẽ

(Aikanã)

peixe gostoso-DEC

'Peixe é gostoso.'

(39)
wikere
tsapi-ka-ẽ
amendoim gostoso-CL:pedaço-DEC

(Aikanã)

'Amendoim é gostoso.'

\section{Raiz vazia}

Uma propriedade dos sistemas de classificação encontráveis na região, que salta à vista, é o papel da raiz vazia. Em várias línguas, um determinado classificador pode ser semanticamente muito específico, com um conteúdo lexical. Às vezes existe uma palavra independente com sentido equivalente, que, como foi supracitado, pode ter dado origem a tal classificador. No entanto, às vezes não existe uma alternativa independente com conteúdo similar. Se for necessário expressar seu sentido numa palavra independente, o classificador pode ser afixado a uma raiz neutra, que não tem um conteúdo semântico próprio. O classificador para líquidos em Kwazá, -mũ, pode ser transformado em um substantivo livre por sufixação à raiz $e^{-}$, cuja função pode ser considerada como formativo nominal (ou nominalizador): 
(40) $e-m \tilde{u}$

(Kwazá)

$\varnothing$-CL:líquido

'líquido'

Essa construção com uma raiz vazia para dar status independente a classificadores, é largamente confirmada nas línguas da região. Além disso, a forma da raiz vazia é muito similar entre as línguas. Os seguintes exemplos mostram a ubiquidade desta construção:

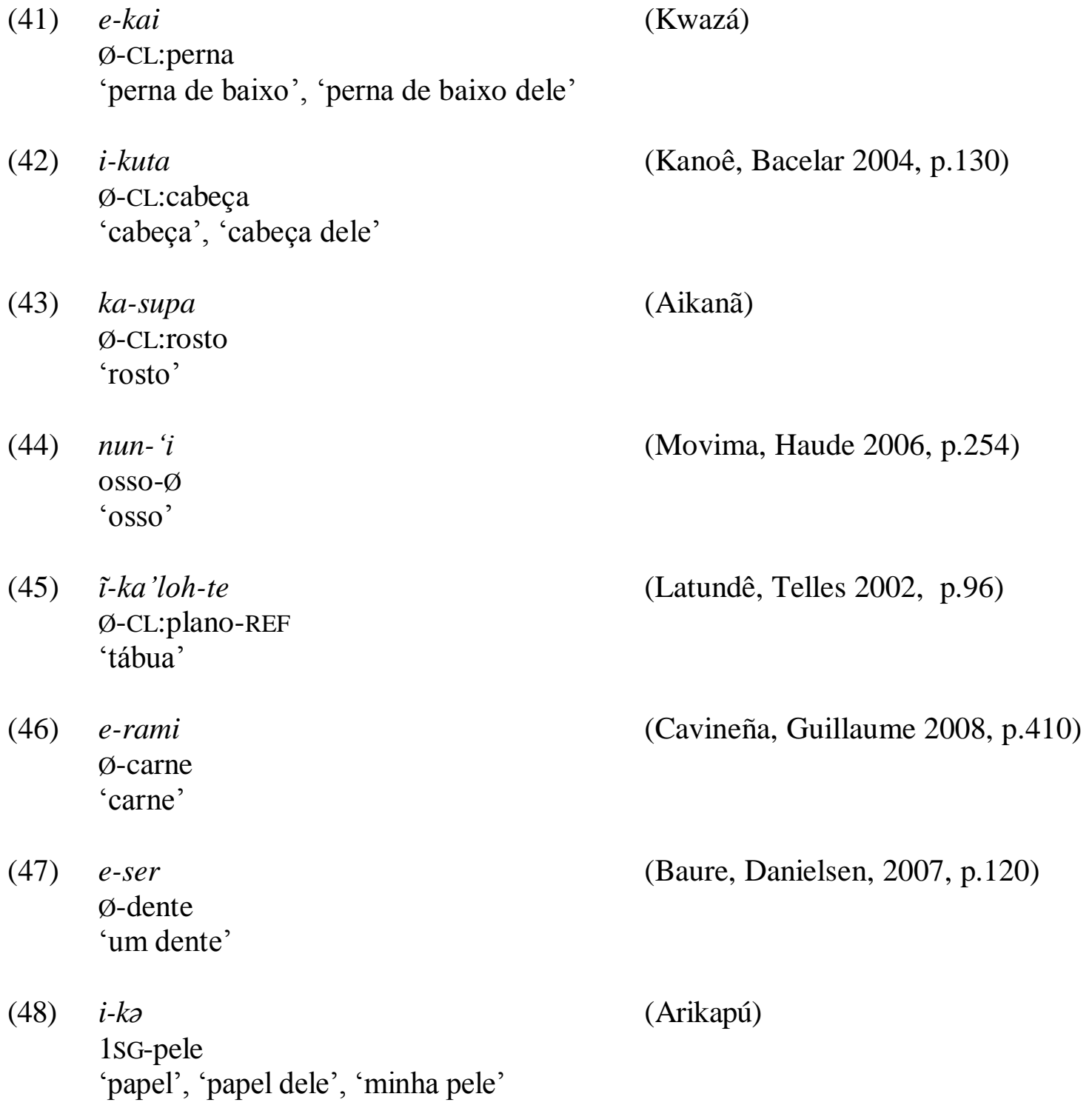

Nota-se que a forma e a natureza dessa construção não são idênticas em todas as línguas. Mesmo que predomine a raíz vazia $e$ - ou $i$-, em Aikanã a raiz é $k a-$. Por sua vez, em Movima, o elemento é representado por um sufixo e o mesmo não é para transformar um morfema preso em um morfema livre; é somente para garantir o número mínimo de sílabas, exigido para todas as palavras independentes. Em Arikapú, trata-se de um prefixo 
de flexão pessoal, usado como morfema dummy ('fantoche'), como foi atestado também na língua irmã Djeoromitxí (CASTRO 2013). Além disso, os elementos "vazios" não são necessariamente analisados assim pelos linguistas referidos neste artigo. Apesar de tudo isso, as semelhanças são notáveis, e, diante da diversidade genética das línguas, são muito provavelmente devidas a contato entre as línguas ou seus ancestrais protolinguísticos. Parece que esse traço areal não se limitou ao Sudoeste amazônico, porque foi atestado também no Noroeste, como por exemplo em Muinane (WITOTO), língua na qual um morfema $i$ - é usado como formativo nominal de classificadores (PETERSEN DE PIÑEROS 2007, VENGOECHA 2005).

\section{Classificadores possessivos}

Em várias línguas da região, classificadores também ocorrem em construções possessivas. Por exemplo, em Kwazá os mesmos classificadores, que ocorrem em outras construções, são também usados em expressões possessivas:

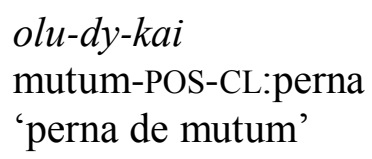

(Kwazá)

Porém, o Kwazá não tem classificadores dedicados a construções possessivas, e, além disso, tais "classificadores possessivos/genitivos" não são especialmente comuns na região. Classificadores possessivos específicos são conhecidos da Oceania (vide, p.ex., LICHTENBERK 2009), mas foram atestados também na América do Sul. Foram descritos para as línguas Macro-Jê por Rodrigues (1997) e foram encontrados em várias línguas do Gran Chaco (MESSINEO; GERZENSTEIN 2007, FABRE 2007). No Sudoeste amazônico ocorre em Yurakaré (ISOLADO, VAN GIJN 2006); em línguas Arawák pelo menos em Baure e, em línguas Tuparí, (TUPI) pelo menos em Mekéns (GALUCIO 2001) e Makuráp (BRAGA 2005). Os seguintes exemplos são ilustrativos da natureza dessa construção:

$$
\begin{aligned}
& \text { o-iko apara } \\
& \text { 1SG-comida banana } \\
& \text { 'minha banana' }
\end{aligned}
$$


'meu frango'

No tronco Tupí, fora do ramo Tupí-Guaraní, classificadores possessivos provavelmente não são comuns. É possível que Mekens e Makurap ou proto-Tuparí adquiriram esta construção por contato com línguas Arawák ou Tupí-Guaraní. O assunto merece uma pesquisa mais aprofundada.

\section{Similaridades formais}

Além de estruturas semelhantes, existem palavras lexicais e morfemas gramaticais que foram difundidas em línguas da região. Em van der Voort (2005, p.386) e Crevels e van der Voort (2008, p.167) foram mencionadas algumas dessas palavras, como os termos para 'milho', 'banana', 'estrela', e morfemas gramaticais, tais como morfemas aplicativos, enfáticos e classificatórios. Na tabela abaixo estão listados os classificadores que têm formas e sentidos similares em línguas da região:

Tabela 3: Difusão areal de classificadores

\begin{tabular}{|l|l|l|l|l|l|}
\hline & Kwazá & Kanoê & Aikanã & Arikapú & Nambikwara \\
\hline casca & $-k a l o$ & & & & $-k a l o,-k a l o h$ \\
\hline osso & $-x u$ & & $-z u$ & & $-s u^{3}$ \\
\hline fruta & $-k o$ & $-k o$ & & & \\
\hline cabelo & $-x y j$ & & $(j i)-d i$ & & \\
\hline líquido & $-m \tilde{u}$ & $-m \tilde{u}$ & $-m \tilde{u}$ & & \\
\hline pamonha & $-m \tilde{\varepsilon}$ & & & $-m \tilde{\varepsilon}$ & \\
\hline pó, massa & $-n \tilde{u}$ & $-n \tilde{u}$ & $-n \tilde{u}$ & $n \tilde{u}$ & $-n \tilde{u} x^{3},-n \tilde{u},-$ inun \\
\hline redondo & $-t \varepsilon$ & $-t c e$ & $-\partial \tilde{a} w$ & & \\
\hline espinho & $-n \tilde{\imath}$ & & & $-n \tilde{\imath}$ & \\
\hline dente & $-m \tilde{a} i$ & & $-m \tilde{u} j$ & & \\
\hline
\end{tabular}

As formas são muito semelhantes, às vezes idênticas, o que sugere que a sua difusão foi relativamente recente. Caso contrário, elas teriam mudado muito mais e se diversificado ao longo do tempo, por causa de processos de desenvolvimento independente nas línguas individuais.

\section{Conclusões}

Por não ser nosso propósito, não ficou enfatizado bastante neste artigo como as línguas da região diferem entre si, não somente do ponto de visto genético-histórico, 
mas também tipologicamente. Contudo, as línguas da região não são muito similares e nem sempre contam com as mesmas categorias. Até mesmo nos sistemas de classificação descritos acima há diferenças consideráveis. O objetivo deste artigo foi mostrar que, apesar dessas diferenças, há traços inegavelmente compartilhados. Por exemplo, tomando-se por base da análise descritiva rigorosa do Movima feita por Haude (2006), essa língua não apresenta uma categoria de classificadores. Porém, em comparação com outras línguas da região, há estruturas na língua que se parecem com as de classificação. A tabela a seguir resume as propriedades dos sistemas de classificação nas línguas da região:

Tabela 4: Propriedades dos sistemas de classificadores

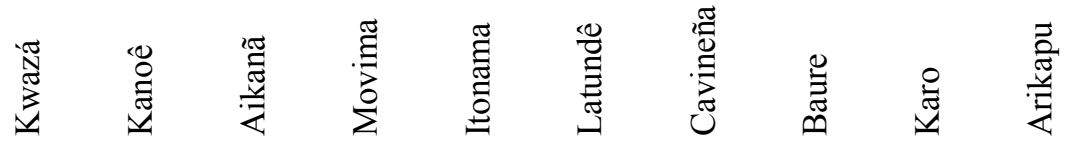

$\begin{array}{lcccccccccc}\text { no. total de CLs } & 150 & 100 & 45 & 70 & 25 & 20 & 130 & 135 & 10 & 10 \\ \text { modificação subst. } & + & + & + & + & + & + & + & + & + & + \\ \text { argumento verbal } & + & + & + & + & + & + & + & + & - & (+) \\ \text { anafórico } & + & + & + & + & & + & & + & - & + \\ \text { concordância } & - & - & + & - & - & + & - & + & + & - \\ \text { nominalização } & + & - & - & + & - & + & - & - & - & - \\ \text { CL genérico } & + & - & - & + & - & (-) & - & - & - & - \\ \text { morfema vazio } & + & + & + & + & - & + & + & + & - & - \\ \text { CL livre } & - & - & - & & & + & (+) & & + & - \\ \text { subst. como CL } & & & + & & & & & + & - & +\end{array}$

A explicação para as semelhanças entre as línguas da região com respeito a, por exemplo, aplicativos, citativos, estruturas possessivas e sistemas de classificação provavelmente não deve ser em termos de relações de parentesco ou em termos de universais tipológicos. A explicação deve ser procurada nos contatos entre os povos, levando à difusão areal de itens lexicais e estruturas gramaticais.

\section{Abreviaturas}

$\mathrm{A}=$ agente; $\mathrm{ABS}=\mathrm{absential} ; \mathrm{ADJ}=$ adjetivo; $\mathrm{ADV}=$ adverbio(/ial); $\mathrm{ANT}=$ anterior; $\mathrm{AO}=\mathrm{objeto}$ animado; $\mathrm{ART}=$ artigo; $\mathrm{BDR}=\mathrm{voz}$ direto bivalento; $\mathrm{BE}=$ elemento preso; $\mathrm{BR}=$ raíz preso; CAUS=causativo; $\quad \mathrm{CD}=$ classificador/direcional; $\mathrm{CL}=$ classificador; $\quad \mathrm{COS}=$ mudança $\mathrm{de}$ estado; $\quad$ DEC=declarativo; $\quad$ DEM=demonstrativo; $F N S=$ sufixo nominal final; IMP=imperativo; IMPF=imperfeito; LK=ligador; M=masculino; NEUT=neutral (aspecto); 
$\mathrm{NOM}=$ nominalizador; $\mathrm{PE}=$ plural exclusivo; $\mathrm{O}=$ objeto; $\mathrm{PI}=$ plural inclusivo; $\mathrm{PL}=$ plural; POS=possesivo; $\quad$ POT=potencial; $\quad$ PRFLX=perfectivo reflexivo; REF=referencial; $\mathrm{SG}=$ singular; $\mathrm{SUB}=$ subordinador; $\mathrm{TRA}=$ transitivizador; $\mathrm{VOL}=$ volitivo

\section{Agradecimentos}

Os dados das línguas Aikanã, Arikapú e Kwazá vêm do meu próprio trabalho de campo. Agradeço às comunidades das T.I.s Tubarão-Latundê, Kwazá do São Pedro, Rio Branco e Rio Guaporé pela hospitalidade. Agradeço mais especificamente aos meus professores Mário Kwazá, Raimunda Aikanã, Manoel Aikanã e Nazaré Arikapú pelo ensino das suas línguas nativas. Agradeço ao Laércio Bacelar os comentários carinhosos e correções cuidadosas. Também agradeço correções ao Sidi Facundes que me incentivou e aceitou meu artigo na última hora. Agradeço à Organização Neerlandesa de Pesquisa Científica (NWO), à Fundação de Amparo à Pesquisa do Estado do Pará (FAPESPA) e à Fundação Volkswagen (VWS, programa DoBeS), o apoio financeiro aos meus projetos de pesquisa e documentação do que este artigo é um dos resultados, e à FUNAI e ao CNPq as autorizações e licenças concedidas. Os meus professores e colegas citados neste artigo não necessariamente concordam com as minhas interpretações. A responsabilidade pelo conteúdo deste artigo é a minha.

\section{REFERÊNCIAS}

AIKHENVALD, A. Y. Classe nominal e gênero nas línguas Aruák. Boletim do Museu Paraense Emílio Goeldi, Antropologia, Belém, v. 10, n. 2, p. 137-259, 1994.

AIKHENVALD, A. Y. Classifiers: a typology of noun classification devices. Oxford: Oxford University Press, 2000.

ALLAN, K. Classifiers. Language, Chicago, v. 53, n. 2, p. 285-311, 1977.

BACELAR, L. N. Gramática da língua Kanoê. Tese doutoral - Katholieke Universiteit Nijmegen, Nijmegen, 2004. Disponível em: <http:// webdoc.ubn.kun.nl/mono/b/bacelar_1/gramdalik.pdf>. Acesso em: 12/02/2014.

BRAGA, A. de Oliveira. Aspects morphosyntaxiques de la langue makurap. Tese doutoral - Université Toulouse II, Toulouse, 2005.

CASTRO, Th. de. Estratégias de categorização nominal em Djeoromitxí. Apostila acompanhando palestra na IV CIELLA, 25 de abril de 2013, UFPA, Belém, 2013. 
CRAIG, C. (Org.). Noun classes and categorization: proceedings of a symposium on categorization and noun classification, Eugene, Oregon, October 1983. Amsterdam/Philadelphia: J. Benjamins, 1986.

CREVELS, M. Itonama. In: CREVELS, M; MUYSKEN, P. (Orgs.), Lenguas de Bolivia, II: Amazonia. La Paz: Plural Editores. 2012, p. 233-294.

CREVELS, M.; VAN DER VOORT, H. The Guaporé-Mamoré region as a linguistic area. In: MUYSKEN, P. (Org.). From linguistic areas to areal linguistics. Amsterdam/Philadelphia: J. Benjamins. 2008, p. 151-179.

DANIELSEN, S. Baure: an Arawak language of Bolivia, ILLA 6. Leiden: CNWS, 2007.

DERBYSHIRE, D. C.; PAYNE, D. L. Noun classification systems of Amazonian languages. In: PAYNE, D. L. (Org.), Amazonian linguistics: Studies in Lowland South American languages. Austin: University of Texas Press. 1990, p. 243-271.

EBERHARD, D. M. Mamaindê grammar: a Northern Nambikwara language and its cultural context. Utrecht: LOT Publications, 2009. Disponível em: $<$ http://www.lotpublications.nl/index3.html $>$. Acesso em: 12/02/2014.

FABRE, A. Morfosintaxis de los clasificadores posesivos en las lenguas del Gran Chaco (Argentina, Bolivia y Paraguay). UniverSOS. Revista de Lenguas Indigenas y Universos Culturales, Valencia, v. 4, p. 67-85, 2007.

GABAS Jr., N. A grammar of Karo, Tupí (Brazil). Tese doutoral - University of California, Santa Barbara, 1999.

GALUCIO, A. V. The morphosyntax of Mekens (Tupi). Tese doutoral - University of Chicago, Chicago, 2001.

GRINEVALD, C. A morphosyntactic typology of classifiers. In: SENFT, G. (Org.), Systems of nominal classification, Cambridge: Cambridge University Press. 2000, p. 5092.

GRINEVALD, C.; SEIFART, F. Noun classes in African and Amazonian languages. Linguistic Typology, Berlin, v. 8, n. 2, p. 243-285, 2004.

GUILLAUME, A. A grammar of Cavineña. Berlin;New York: Mouton de Gruyter, 2008.

HALE, K.; KRAUSS, M.; WATAHOMIGIE, L. J.; YAMAMOTO, A. Y.; CRAIG, C.; LAVERNE MASAYESVA, J.; ENGLAND, N. C. Endangered languages. Language, Chicago, v. 68, n.1, p. 1-42, 1992.

HAUDE, K. A grammar of Movima. Tese doutoral - Radboud Universiteit, Nijmegen, 2006. Disponível em: <http://webdoc.ubn.ru.nl/mono/h/haude_k/gramofmo.pdf>. Acesso em: 12/02/2014. 
LICHTENBERK, F. Attributive possessive constructions in Oceanic. In: MCGREGOR, W. B. (Org.), The expression of possession. Berlin; New York: Mouton de Gruyter. 2009, p. 249-292.

MESSINEO, C.; GERZENSTEIN, A. La posesión en dos lenguas indígenas del Gran Chaco: toba (guaycurú) y maká (mataguayo). Línguas Indígenas Americanas (LIAMES), Campinas, v.. 7, p. 61-79, 2007.

PAYNE, D. L. Noun classification in the Western Amazon. Language Sciences, s.l., vol. 9 / n. 1, p. 21-44, 1987.

PETERSEN DE PIÑEROS, G. Nominal classification in Uitoto. International Journal of American Linguistics, Chicago, v. 73, n. 4, p. 389-409, 2007.

RODRIGUES, A. D. Nominal classification in Karirí. Opción, Maracaibo, v. 13, n. 22, p. 65-79, 1997.

SEIFART, F.; PAYNE , D. L. Nominal classification in the North West Amazon: issues in areal diffusion and typological characterization. International Journal of American Linguistics, Chicago, v. 73, n. 4, p. 381-387, 2007.

TELLES, S. Fonologia e gramática Latundê/Lakondê. Tese doutoral - Vrije Universiteit, Amsterdam, 2002.

VAN DER VOORT, H. Kwaza in a comparative perspective. International Journal of American Linguistics, Chicago, v. 71, n. 4, p. 365-412, 2005.

VAN DER VOORT, H. Fala fictícia fossilizada: o tempo futuro em Aikanã. Boletim do Museu Paraense Emílio Goeldi (Ciências Humanas), Belém, v. 8, n. 2, p. 359-377, 2013. Disponível em: <http://www.scielo.br/pdf/bgoeldi/v8n2/09.pdf>. Acesso em: $12 / 02 / 2014$.

VAN DER VOORT, H. Development and diffusion of classifier systems in Southwestern Amazonia. In: WICHMANN, S.; MCGREGOR, W. B. (Orgs.). The diachrony of classification. Amsterdam; Philadelphia: J. Benjamins. No prelo.

VAN GIJN, R. A grammar of Yurakaré. Tese doutoral - Radboud Universiteit, Nijmegen, $2006 . \quad$ Disponível em: <http://webdoc.ubn.ru.nl/mono/g/gijn_e_van/gramofyu.pdf>. Acesso em: 12/02/2014.

VENGOECHEA, C. Morphosyntax of Muinane: typological remarks. Amerindia, revue d'ethnolinguistique amerindienne, Villejuif, v. 29-30, p. 119-140, 2005. 